\section{Carbohydrate and Nutritional Responses to Stem Girdling and Drought Stress with Respect to Understanding Symptoms of Huanglongbing in Citrus}

\author{
Giuseppe Cimò and Riccardo Lo Bianco \\ University of Palermo, Department of Agricultural and Forestry Sciences, \\ Viale delle Scienze 11, 90128, Palermo, Italy
}

Pedro Gonzalez, Wije Bandaranayake, Edgardo Etxeberria, and James P. Syvertsen ${ }^{1}$

University of Florida, IFAS, Citrus Research and Education Center, 700 Experiment Station Road, Lake Alfred, FL 33850

Additional index words. citrus greening, drought stress, leaf and root starch, leaf gas exchange, mineral nutrition, stem girdling, HLB

\begin{abstract}
The most important worldwide problem in citrus production is the bacterial disease Huanglongbing (HLB; citrus greening) caused by a phloem-limited bacterium Candidatus Liberibacter asiaticus. The earliest visible symptoms of HLB on leaves are vein yellowing and an asymmetrical chlorosis referred to as "blotchy mottle," thought to be the result of starch accumulation. We tested the hypothesis that such visible symptoms are not unique to HLB by stem girdling 2-year-old seedlings of two citrus rootstocks with and without drought stress in the greenhouse. After 31 days, girdling had little effect on shoot growth but girdling increased the relative growth rate of shoots in drought-stressed trees. Starch content in woody roots of non-girdled trees was three to 19 times higher than in girdled trees. In non-girdled trees, drought stress induced some starch accumulation in roots, but there were no effects of drought stress on root starch or sucrose in girdled trees. Girdling induced a 4-fold greater starch content in leaves on well-watered trees but leaf sucrose content was unaffected. Girdling reduced leaf transpiration in well-watered trees but net assimilation of $\mathrm{CO}_{2}$ was unaffected by girdling or leaf starch accumulation. Leaves on girdled trees clearly had visible blotchy mottle symptoms but no symptoms developed on non-girdled trees. The increase in leaf starch, up to $50 \%$ dry weight (DW), resulted in an increase in leaf DW per leaf area (LA) and an artificial reduction of many leaf nutrients on a DW basis. Most of these differences disappeared when expressed on a LA basis. Leaf boron (B), however, was inversely related to leaf starch when both were expressed on a $L A$ basis. In the absence of HLB, girdling increased leaf starch, decreased root starch, and duplicated the asymmetric blotchy mottled visual leaf symptoms that have been associated with HLB-infected trees. This supports our contention that such symptoms generally attributed to HLB are not uniquely related to HLB infection, but rather are directly related to starch accumulation and secondarily to nutrient deficiencies in leaves.
\end{abstract}

Currently, the most important problem in citrus production worldwide is the bacterial disease HLB (syn. citrus greening). HLB is presumably caused by the bacterium Candidatus Liberibacter asiaticus (Clas), a fastidious Gram-negative, obligate parasite, phloem-limited $\alpha$-proteobacterium (Garnier and Bove, 1983; Jagoueix et al., 1994). When vectored into a citrus tree by phloem-feeding psyllids, Clas triggers a cascade of events causing phloem dysfunction, cellular collapse, and overaccumulation of carbohydrates in leaves (Bove, 2006; Garnier and Bove, 1983). The earliest visible symptoms of HLB in

Received for publication 4 Apr. 2013. Accepted for publication 9 May 2013.

${ }^{1}$ To whom reprint requests should be addressed; e-mailjmsn@ufl.edu. in mineral nutrition in the shoot (Spann and Schumann, 2009). Thus, secondary symptoms resulting from mineral deficiency often complicate the diagnosis of HLB symptoms (related to starch accumulation in leaves; Etxeberria et al., 2009) from those caused by mineral nutrient imbalances (Spann and Schumann, 2009).

Stem girdling has been widely used in citrus, grape, peach, and other fruit tree crops, mainly to increase flowering, fruit set, and fruit size (Goren et al., 2004). Girdling is the removal of a strip of bark with included phloem tissue from the trunk or major limbs of a fruit tree, thereby blocking the downward translocation of photosynthetic carbohydrates and metabolites through the phloem. The best known effects of girdling are the accumulation of assimilates, sugars, and starch above the girdle area (Goren et al., 2004). Tree parts below the girdle, on the other hand, can suffer from a shortage of assimilates. After trunk girdling, the roots are gradually depleted of their carbohydrate reserves, sometimes reaching serious root starvation (Weaver and McCune, 1959). Cytokinin and gibberellins content of shoots can also be disturbed by girdling (Cutting and Lyne, 1993). However, the precise biochemical changes resulting from girdling have been studied only in a few particular cases (Beruter and Feusi, 1997), and a detailed interpretation of the physiological effects of girdling is still lacking. Progress in tree research during the past decade has led to the understanding that, beyond their nutritional and energetic contribution, sugars can play regulatory roles, which involve up- and downregulation of gene expression (Jang and Sheen, 1997; Koch and Zeng, 2002; Smeekens, 2000).

Gonzalez et al. (2012) showed that girdled 'Valencia' citrus trees accumulated large amounts of starch producing symptoms analogous to those characteristic of HLBaffected tissues. Starch grains from both HLB and girdled trees were morphologically similar with only small biochemical difference in glucan chain lengths. This similarity prompted us to investigate the increase in starch concentration through time using girdled citrus trees of Cleopatra and Swingle rootstocks exposed to water deficit. The aim of this study was to determine which HLBlike symptoms were related to starch accumulation and/or drought stress in the absence of any HLB infection. Girdling of the stem bark was intended to mimic the decreased carbohydrate transport caused by the phloem dysfunction in HLB-affected trees. We hypothesized that both girdling and drought stress should lead to measurable changes in tree growth, starch allocation, and mineral nutrient composition that are similar to those reported for HLB. Understanding these responses will contribute to our knowledge of symptom development in HLB because some symptoms may be the result of secondary responses of carbohydrate accumulation and, thus, only indirectly related to HLB. 


\section{Materials and Methods}

Tree material and experimental design. Forty-eight uniform, well-nourished 2-yearold seedlings of Swingle citrumelo (Citrus paradise Macf. $\times$ Poncirus trifoliata $\mathrm{L}$.) with trifoliate leaves and Cleopatra mandarin $(C$. reticulata Blanco) with entire leaves were purchased from a local nursery certified free of HLB. Seedling trees were $\approx 180 \mathrm{~cm}$ tall and grown in 2.25 -L pots filled with a soilless media consisting of peat/sponge-rock/ vermiculite (3:1:1). Trees were grown in an unshaded greenhouse from 29 May to 29 June 2012 at the University of Florida/IFAS Citrus Research and Education Center, Lake Alfred, FL (lat. $28^{\circ} \mathrm{N}$, long. $82^{\circ} \mathrm{W}$, elevation $51 \mathrm{~m}$ ). Maximum photosynthetically active radiation $(P A R)$ at tree level was $\approx 1200 \mu \mathrm{mol} \cdot \mathrm{m}^{-2} \cdot \mathrm{s}^{-1}$ (LI-170; LICOR, Inc., Lincoln, NE). Average day/night temperature was $40 / 30{ }^{\circ} \mathrm{C}$ and relative humidity $(\mathrm{RH})$ varied diurnally from $40 \%$ to $100 \%$.

Each cultivar was divided into four treatment groups (with six trees per treatment). The treatments were: 1) non-girdled and wellwatered (control); 2) non-girdled and droughtstressed; 3) girdled and well-watered; and 4) girdled and drought-stressed.

Well-watered trees were thoroughly irrigated three times a week, whereas droughtstressed trees were irrigated only when wilting symptoms appeared, which averaged approximately once per week. All trees were fertilized once a week with $\approx 600 \mathrm{~mL}$ of complete fertilizer solution containing chelated iron $(\mathrm{Fe}$; $\left.1 \mathrm{~mL} \cdot \mathrm{L}^{-1}\right), 7 \mathrm{~N}-3 \mathrm{P}-7 \mathrm{~K}$, and all micronutrients. No psyllids were ever observed but for preventative pest control, trees were sprayed once a week with either $1 \%$ agricultural spray oil or $1 \%$ soap solution.

Total stem length and basal stem diameter, above and below the girdled area and at a similar height for non-girdled trees, were measured at time zero and again at the end of the experiment, $32 \mathrm{~d}$ later. Stem relative growth rate (RGR) was calculated using the difference between total stem length at the beginning and the end of the experiment divided by the number of elapsed days between the two measurements $\left(\mathrm{cm} \cdot \mathrm{m}^{-1} \cdot \mathrm{d}^{-1}\right)$. Girdling was performed on 29 May 2012 on the main stem $20 \mathrm{~cm}$ above the pot. A ring of stem bark tissue $(\approx 4 \mathrm{~mm}$ in width) was carefully removed (Fig. 1A) using a pair of razor blades glued together with a space of $4 \mathrm{~mm}$ between them. The girdled strip was renewed every $9 \mathrm{~d}$ to prevent healing and phloem repair.

Preliminary experiment. A preliminary experiment was conducted with 16 additional trees of the same two rootstocks, using two replicate trees per treatment, from 24 Apr. to 15 May 2012. Six leaf disk samples per tree (three disks per leaf/two leaves per tree) were sampled and used to evaluate starch, sucrose, and DW per area (DW/LA) on the day of girdling (time zero) and at 3, 7, 10, 13, 14, and $21 \mathrm{~d}$ after girdling. The analyses did not show any difference in starch and sucrose content between disk samples from the same leaf. Starch content was still increasing at $21 \mathrm{~d}$ after girdling (data not shown). Based on these results, we decided to reduce the number of samples per leaf and extend experimental time up to $31 \mathrm{~d}$ to determine any changes in the rate of carbohydrate accumulation. Two weeks after girdling, a few new shoots developed directly below the girdle in some trees but not all (Fig. 1B). At harvest, these were removed and starch was analyzed using these entire shoots as sampling units. Although gas exchange, water relations, and nutrient analysis were also determined, only data from the second ( $32 \mathrm{~d}$ ) experiment are presented.

Leaf and root sampling. Based on the preliminary experiment, four disk samples per tree (two disks per leaf/two leaves per tree) of an area equal to $28 \mathrm{~mm}^{2}$ each were taken at the same time each morning using a sharp leaf punch. All samples were taken from mature leaves (4 to 7 months old) and used to evaluate starch and sucrose on the day of girdling (time zero) and then at 3, 8, 10, 13, $17,21,24,28$, and $31 \mathrm{~d}$ after girdling. Two disks from each leaf were stored in a single mini-plastic tube and frozen at $-4{ }^{\circ} \mathrm{C}$ until analysis. The remaining two disks were weighed, put in an envelope, and dried for $24 \mathrm{~h}$ at $60^{\circ} \mathrm{C}$ to calculate leaf DW/LA. All disk samples were taken from the same tree height, at about midstem, from different orientations. Six disks were averaged to give a single value for each tree.

Stem diameters above and below the girdle and total stem length were measured at the beginning and the end of the experiment and used to calculate stem growth rates. At the end of the experiment $(31 \mathrm{~d}$ after girdling), roots were washed and divided into two size categories, i.e., woody (diameter greater than $2 \mathrm{~mm}$ ) and fibrous (diameter less than $2 \mathrm{~mm}$ ). Separate root categories were dried at $100{ }^{\circ} \mathrm{C}$ for $1 \mathrm{~h}$ to stop respiration; the temperature then was dropped to $60{ }^{\circ} \mathrm{C}$ for $48 \mathrm{~h}$ until complete dryness. Dried roots
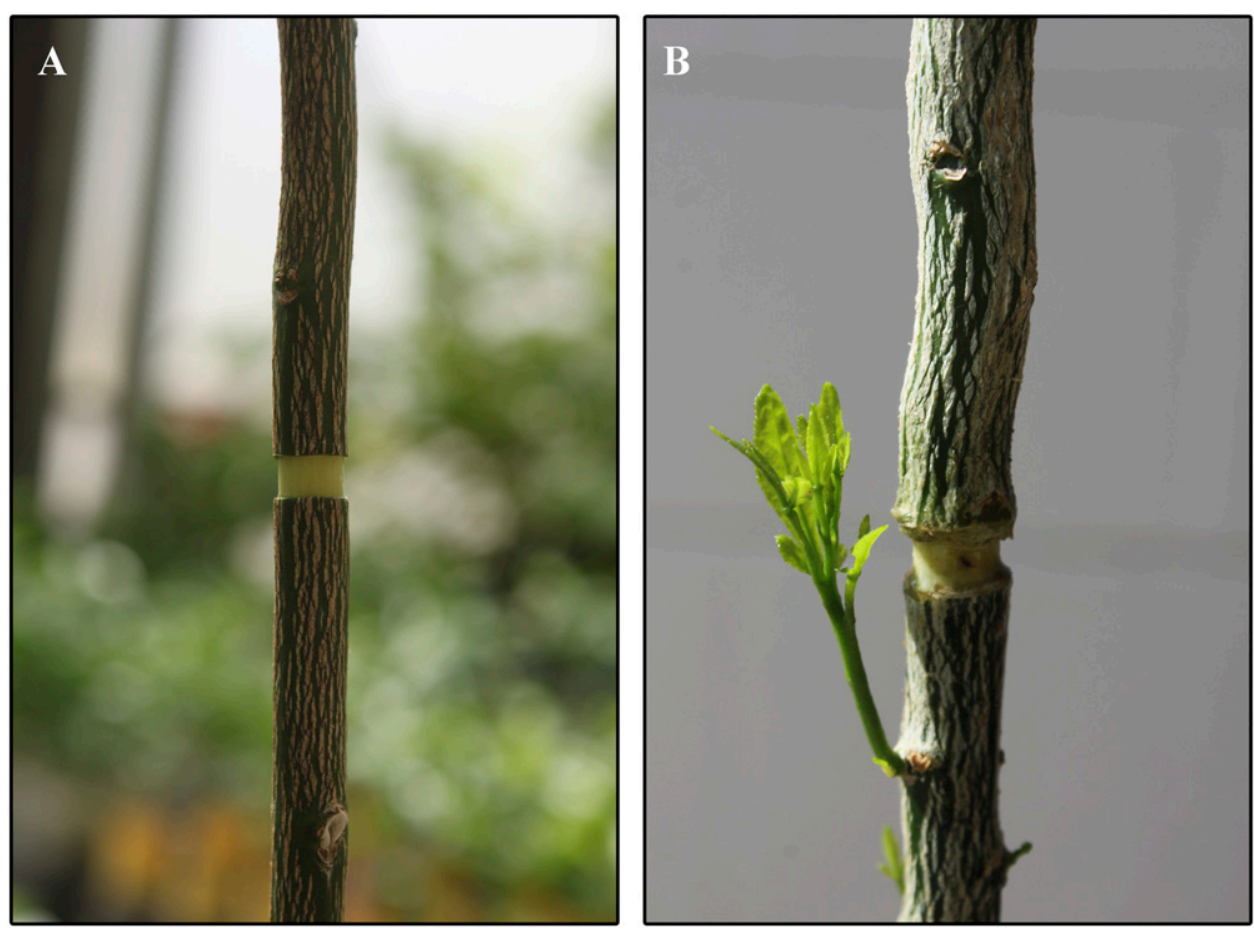

Fig. 1. Newly girdled Swingle citrumelo tree (A) and shoot development on the basipetal side of the girdled area after $15 \mathrm{~d}(\mathbf{B})$. Note stem thickening beginning above the girdle. 
were ground to powder using a Marathon Electric Grinder (Model 5KH39QN5525A; Wausau, WI).

Starch and sucrose determinations. Starch was quantified according to the method of Gonzalez and Etxeberria (Rosales and Burns, 2011). Two disks of fresh leaf tissue (total of $56 \mathrm{~mm}^{2} /$ tree) were homogenized in a $2.5-\mathrm{mL}$ tube containing $1 \mathrm{~mL}$ of distilled water and five metal beads $(2.38 \mathrm{~mm}$ in diameter). Homogenization was carried out in a Precellys 24 homogenizer at $6500 \mathrm{rpm}$ (Bertin Technologies, Montigny-le-Bretonneux, France). After homogenization, the metal beads were removed from each tube and the homogenate boiled for $10 \mathrm{~min}$ in a water bath. Samples were subsequently agitated in a Vortex mixer and then centrifuged in an Eppendorf AG Centrifuge Model 5417C, swinging bucket rotor (Eppendorf AG, Hamburg, Germany) for $2 \mathrm{~min}$ at $665 \times g$ to eliminate any residual unbroken tissue. The supernatant was used for starch and sucrose determination.

For starch determination, $300 \mu \mathrm{L}$ of supernatant was mixed with $900 \mu \mathrm{L}$ of $100 \%$ ethanol, thoroughly mixed in a vortex mixer, and centrifuged for $5 \mathrm{~min}$ in a microcentrifuge (Model 16K; BIO-RAD Laboratories, Hercules, CA) at $14,800 \times g$ to isolate the starch pellet. The supernatant was discarded and the starch pellet re-suspended in $1 \mathrm{~mL}$ of distilled water by vigorous agitation in a vortex mixer. For color development, $50 \mu \mathrm{L}$ of $\mathrm{KI}_{2}$ solution (2 $\mathrm{g} \mathrm{I}_{2}$ plus $20 \mathrm{~g} \mathrm{KI}$ per liter) was added. Quantification of starch was accomplished by monitoring color change at $594 \mathrm{~nm}$ in a BIORAD Microplate Spectrophotometer (Model 680) connected to a Thermal Printer (Model DPU 414; Biorad Laboratories, Hercules, CA). Rice starch (Sigma Aldrich, St. Louis, MO) was used as a standard.

Sucrose was determined according to the method of Van Handel (1968). One hundred microliters of supernatant and standard solutions were mixed with $100 \mu \mathrm{L}$ of $30 \% \mathrm{KOH}$ and boiled for $10 \mathrm{~min}$. Three microliters of anthrone reagent $(0.14 \%$ anthrone in $25.8 \mathrm{~N}$ $\mathrm{H}_{2} \mathrm{SO}_{4}$ ) was added to each tube and thoroughly mixed. The mixture was incubated at $40{ }^{\circ} \mathrm{C}$ for $20 \mathrm{~min}$ and agitated once more to homogenize the color. Quantification was carried out with a PharmaSpect ultraviolet 1700, ultraviolet-visible spectrophotometer (Shimadzu Corporation, Kyoto, Japan) at $620 \mathrm{~nm}$. For woody and fibrous root tissues, $\approx 0.02 \mathrm{~g}$ of dry material was homogenized and used for starch and sucrose determination as described previously for leaves.

Visual detection of starch with iodine staining. Starch determinations were corroborated by iodine staining of fresh tissue. Leaves, petioles, and roots were collected from each treatment at the end of the experiment. Samples were hand-sectioned perpendicular to the long axis with a sharp razor blade and immediately immersed in a $\mathrm{KI}_{2}$ solution at room temperature. Optimal staining was obtained within 2 min, after which the sections were observed under a Wild Heerbrugg stereoscope (Wild Heerbrugg
Instruments, Ltd., Heerbrugg, Switzerland). Images were captured with a Canon PowerShot S3 IS (Martin Microscope Co., Easley, SC).

Gas exchange, stem water potential, and nutrients. Net gas exchange $\left[\mathrm{CO}_{2}\right.$ assimilation rate $\left(\mathrm{ACO}_{2}\right)$, leaf transpiration rate $\left(\mathrm{E}_{\mathrm{lf}}\right)$, stomatal conductance $\left(g_{\mathrm{s}},\right)$, and water use efficiency (WUE)] were determined with a LI-COR portable photosynthesis system (LI-6400; LI-COR Inc., Lincoln, NE). All measurements were taken in the morning from $\approx 0900$ to $1130 \mathrm{HR}$ to avoid high afternoon temperatures and low humidity, which can reduce net gas exchange (Hu et al., 2007; Jifon and Syvertsen, 2003) under saturating $P A R$ $\left(550 \mu \mathrm{mol} \cdot \mathrm{m}^{-2} \cdot \mathrm{s}^{-1}\right)$, leaf temperature of $30 \pm$ $2{ }^{\circ} \mathrm{C}$, and vapor pressure deficit of $2.4 \pm 0.4 \mathrm{kPa}$ within the cuvette. Fully expanded mature leaves from the midstem area on each of the six replicate trees were used for all measurements.

Stem water potential $\left(\mathrm{WP}_{\mathrm{S}}\right)$ was measured, before and after watering, using a pressure chamber (Model 3115; SAPS II, System Analysis of Tree Stress, Soil Moisture Equipment Corp., Santa Barbara, CA). One single mature leaf per tree was first covered with an aluminum bag for a period of $2 \mathrm{~h}$. Afterward, the leaf was cut off, sealed in the chamber with the petiole protruding, pressurized, and the escape of the first liquid bubble was observed with a magnifying glass (PerézPeréz et al., 2007).

Whole tree transpiration $\left(\mathrm{E}_{\mathrm{p}}\right)$ was measured after watering each tree and allowing enough time for excess water to drain. Each pot was covered using a plastic bag $(15 \mathrm{~L})$ sealed around the stem base. Pots were weighed after 24 and $48 \mathrm{~h}$ under greenhouse conditions (maximum temperature $=38^{\circ} \mathrm{C}$ at $75 \%$ $\mathrm{RH}$ ) and the two daily values averaged. Trees were harvested $32 \mathrm{~d}$ after girdling and at the end of the drought stress cycle. In each tree, total LA was measured using a portable LA meter (Model LI-3050C + LI-3000C; LICOR Inc., Lincoln, NE) and used to calculate $\mathrm{E}_{\mathrm{p}}$ in units of $\mathrm{g} \cdot \mathrm{m}^{-2} \cdot \mathrm{h}^{-1}$.

Leaves were dried at $60{ }^{\circ} \mathrm{C}$ for $48 \mathrm{~h}$ to calculate DW. Dried leaves were ground to powder using a Cyclone Sample Mill Grinder (Model 3010-080P; UDY Corporation, Fort Collins, $\mathrm{CO}$ ) and sent to the Waters Agricultural Laboratories (Camilla, GA) in plastic vials to quantify micro- and macronutrients. Tissue nutrient analysis was done using a wet digestion method and analyzed by inductively coupled plasma-mass spectrometry. Nitrogen was quantified separately using a combustion method (LECO TruSpec, St. Joseph, MI).

Statistical analysis. Rootstock, girdling, and drought stress effects were analyzed as a completely randomized $2 \times 2 \times 2$ design using analysis of variance from Statistical Analysis System for PC (SAS Institute Inc., Cary, NC). Tukey's honestly significant difference was used to separate means when interactions among main factors were present. Regression analyses of selected variables were used to fit response lines and to investigate associations.

\section{Results}

Tree growth. Regardless of rootstock, drought stress significantly decreased stem RGR in non-girdled trees after $31 \mathrm{~d}$ (Table 1). Girdling had little effect on shoot growth but girdling increased the RGR of stems in drought-stressed trees. Although many girdled trees developed thickened stems above the girdle (Fig. 1B), there were no significant differences in stem diameter growth or total LA among treatments after $31 \mathrm{~d}$ (data not shown). Two weeks after girdling, basal sprouting (Noel, 1970) of new shoots developed in some trees directly below the girdled area but no new shoots appeared on nongirdled trees.

In both rootstocks, there was a significant increase in leaf DW/LA on girdled trees compared with the non-girdled trees, and Cleopatra leaves (Fig. 2A) tended to have greater DW/LA than trifoliate Swingle leaves (Fig. 2B). In particular, DW/LA increased rapidly in the first 2 weeks of the experiment and leveled off by the end of the $31 \mathrm{~d}$ as indicated by the exponential model used to fit the data. Although drought stress tended to decrease leaf DW/LA on girdled Swingle trees, overall, there were no significant differences in the rate of DW/LA change between well-watered and drought-stressed trees (Fig. 2).

Starch and sucrose content in leaves. On a LA basis, Swingle had higher starch but lower sucrose content than Cleopatra leaves at the end of the experiment (Table 2). Girdling induced a 4-fold increase of leaf starch content over non-girdled leaves but leaf sucrose content was unaffected. Drought stress induced only minor, non-significant reductions of starch and sucrose contents compared with well-watered control trees (Table 2). An overall positive relationship was found between sucrose and starch (slope $=8.68, R^{2}=0.184, P<0.001$ ).

Similar to leaf DW/LA (Fig. 2), there was a significant increase of leaf starch per unit area in girdled trees compared with the nongirdled trees for both rootstocks (Fig. 3). In Cleopatra, starch increased rapidly during the first 2 weeks of the experiment and leveled off after $31 \mathrm{~d}$ as indicated by the exponential model used to fit the data (Fig. 3A). In Swingle, starch increased more gradually and continually during the observed timeframe, especially in drought-stressed trees

Table 1. Daily stem relative growth rate (RGR) for the Cleopatra and Swingle trees during the 31-d experiment.

\begin{tabular}{lcc}
\hline Girdling & Drought stress & $\begin{array}{c}\text { RGR } \\
\left(\mathrm{cm} \cdot \mathrm{m}^{-1} \cdot \mathrm{d}^{-1}\right)\end{array}$ \\
\hline NG & WW & 0.657 \\
& DS & 0.161 \\
G & WW & 0.536 \\
& DS & 0.586 \\
& HSD & 0.346 \\
& $P$ (girdling $\times$ drought & 0.009 \\
& stress) & \\
\hline
\end{tabular}

$\mathrm{NG}=$ non-girdled; $\mathrm{G}=$ girdled; $\mathrm{WW}=$ well-watered; $\mathrm{DS}=$ drought-stressed; HSD $=$ Tukey's honestly significant difference at $P<0.05$. 


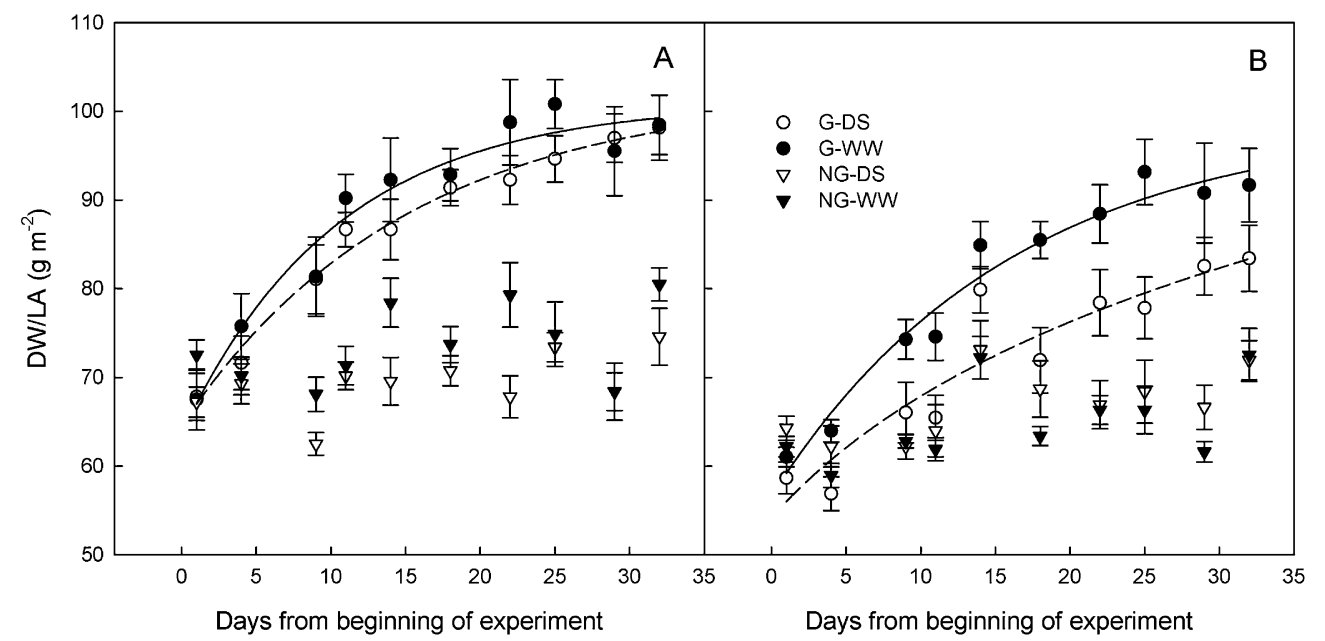

Fig. 2. Changes in leaf dry weight (DW) per unit leaf area (LA) during 31 d under various treatments $(\mathrm{G}=$ girdled; $N G=$ non-girdled; $D S=$ drought-stressed; WW = well-watered) for Cleopatra $(\mathbf{A})$ and Swingle $(\mathbf{B})$ trees. Error bars indicate sems $(\mathrm{n}=6)$. In Cleopatra, DW/LA $\mathrm{G}_{-\mathrm{WW}}=63.6+37.3\left(1-0.91^{\mathrm{d}}\right), R^{2}=0.954$; $\mathrm{DW} / \mathrm{LA}_{\mathrm{G}-\mathrm{DS}}=64.6+37.6\left(1-0.94^{\mathrm{d}}\right), R^{2}=0.986$. In Swingle, $\mathrm{DW} / \mathrm{LA}{ }_{\mathrm{G}-\mathrm{WW}}=56.6+42.4\left(1-0.94^{\mathrm{d}}\right), R^{2}=0.964 ; \mathrm{DW} / \mathrm{LA}{ }_{\mathrm{G}-\mathrm{DS}}=22.1 \mathrm{Ln}|(\mathrm{d}+11.6)|, R^{2}=$ 0.867 . All models are significant at $P<0.05$.

Table 2. Starch and sucrose content $\left(\mathrm{mg} \cdot \mathrm{m}^{-2}\right.$ leaf area) in mature leaves of the two rootstocks after $31 \mathrm{~d}$ of the various treatments. ${ }^{\mathrm{z}}$

\begin{tabular}{lccc}
\hline Factor & Level & Starch & Sucrose \\
\hline Rootstock & Cleopatra & 24.2 & 3.49 \\
& Swingle & 31.1 & 2.60 \\
Girdling & $P$ & 0.067 & $<0.001$ \\
& $\mathrm{G}$ & 44.2 & 3.11 \\
& $\mathrm{NG}$ & 11.0 & 2.99 \\
Drought stress & $P$ & $<0.001$ & 0.460 \\
& $\mathrm{WW}$ & 30.7 & 3.14 \\
& $\mathrm{DS}$ & 24.5 & 2.96 \\
& $P$ & 0.096 & 0.285 \\
\hline
\end{tabular}

zThere were no significant interactions among factors.

$\mathrm{G}=$ girdled; $\mathrm{NG}=$ non-girdled; $\mathrm{WW}=$ well-watered; DS $=$ drought-stressed.

(Fig. 3B). There was no significant difference between well-watered and droughtstressed trees. There were no significant girdling or drought stress effects on leaf sucrose accumulation through time (data not shown).

In girdled Cleopatra trees, asymmetrical blotchy mottle patterns were evident on leaves when starch accumulated (Fig. 4A). These patterns appear identical to those associated with HLB trees in the field (Fig. 4, inset). On non-girdled trees, which did not accumulate starch, no leaf yellowing occurred (Fig. 4B). Similar symptoms were observed in leaves on Swingle trees (data not shown).

Carbohydrate content in roots and new shoots. In both woody (greater than $2 \mathrm{~mm}$ diameter) and fibrous roots (less than $2 \mathrm{~mm}$ diameter), there were significant interactions among treatment factors; starch content was significantly higher in the non-girdled than in girdled roots, especially in Cleopatra (Table $3)$. Woody root starch content of non-girdled trees was seven to 19 times higher in Cleopatra and three to four times higher in Swingle than in girdled trees. Overall, woody roots had higher starch content than fibrous roots but girdling had similar effects in fibrous roots. In non-girdled trees, and particularly for Cleopatra, drought stress induced some starch accumulation. There was no effect of drought stress on the relatively low root starch in girdled trees. Sucrose was also reduced by girdling (data not shown).

Regardless of rootstock, starch levels in new basal shoots of girdled trees were lower $(P=0.031)$ in drought-stressed $\left(27.6 \mathrm{mg} \cdot \mathrm{g}^{-1}\right)$ than in well-watered trees $\left(34.8 \mathrm{mg} \cdot \mathrm{g}^{-1}\right)$ and lower in basal shoots than in mature leaves when expressed on a DW basis (data not shown). Also, the average starch in new shoots of girdled Swingle trees $\left(24.7 \mathrm{mg} \cdot \mathrm{g}^{-1}\right)$ was less $(P=0.002)$ than starch in new shoots of Cleopatra trees $\left(36.9 \mathrm{mg} \cdot \mathrm{g}^{-1}\right)$.

Visualization of starch with iodine staining. The iodine test clearly showed visual differences in starch content between mature leaves and roots $31 \mathrm{~d}$ after girdling (Fig. 5). The visible differences in starch content supported the spectrophotometric determinations.

Net gas exchange. Leaf gas exchange was variable because there were significant interactions among factors for all measured variables except $\mathrm{ACO}_{2}$ (Table 4). Reductions in $\mathrm{ACO}_{2}$ from girdling were not significant. Swingle leaves exhibited higher rates of $\mathrm{ACO}_{2}$ than Cleopatra $(P<0.001)$ and drought stress reduced $\mathrm{ACO}_{2}(P<0.001)$. Drought stress significantly reduced $\mathrm{E}_{\mathrm{lf}}, g_{\mathrm{s}}$, and ratio of internal to ambient $\mathrm{CO}_{2}(\mathrm{Ci} / \mathrm{Ca})$ and increased WUE in Swingle non-girdled trees. Overall, girdling significantly reduced $(P<$ 0.001 ) average $\mathrm{E}_{\mathrm{p}}$ from 875 (in non-girdled) to 616 (girdled) $\mathrm{g} \cdot \mathrm{m}^{-2} \mathrm{~d}^{-1}$ independent of rootstock and drought stress. Drought stress also significantly reduced $(P<0.001) \mathrm{E}_{\mathrm{p}}$ from 857 (well-watered) to 635 (droughtstressed) $\mathrm{g} \cdot \mathrm{m}^{-2} \cdot \mathrm{d}^{-1}$. Regression analysis revealed a negative relationship (slope $=-22.7$, $R^{2}=0.209, P=0.032$ ) between $\mathrm{Ci} / \mathrm{Ca}$ and $\mathrm{ACO}_{2}$ for Cleopatra and a positive relationship (slope $=12.4, R^{2}=0.165, P=0.049$ ) for Swingle. Overall, there were significant correlations among $\mathrm{ACO}_{2}, \mathrm{E}_{\mathrm{lf}}, g_{\mathrm{s}}$, and $\mathrm{E}_{\mathrm{p}}$ (data not shown) but $\mathrm{ACO}_{2}$ was unaffected by girdling or leaf starch accumulation.

Stem water potential. There were significant interactions among treatment factors on leaf $\mathrm{WP}_{\mathrm{S}}$ before and after watering. Before watering, all drought-stressed trees had lower $\mathrm{WP}_{\mathrm{S}}$ than well-watered trees (Table 5). After watering, only non-girdled Cleopatra trees had lower $\mathrm{WP}_{\mathrm{S}}$ in previously water-stressed trees than in well-watered trees. In addition, girdled trees recovered to higher $\mathrm{WP}_{\mathrm{S}}$ than non-girdled trees.

Before watering, there was a significant positive relationship between $\mathrm{WP}_{\mathrm{S}}$ and $\mathrm{ACO}_{2}$ in Swingle (slope $=2.07, R^{2}=0.273, P=$ $0.009 ; \mathrm{ACO}_{2}$ decreased with negative $\mathrm{WP}_{\mathrm{S}}$ ), but not in Cleopatra (slope $=0.92, R^{2}=0.062$, $P=0.252$ ). After watering, however, no significant relationship was detected between $\mathrm{WP}_{\mathrm{S}}$ and $\mathrm{ACO}_{2}$. Also, there was a negative relationship between $\mathrm{WP}_{\mathrm{S}}$ and $\mathrm{Ci} / \mathrm{Ca}$ in Cleopatra (slope $=-0.07, R^{2}=0.313, P=$ 0.004; $\mathrm{Ci} / \mathrm{Ca}$ decreased increased $\left.\mathrm{WP}_{\mathrm{S}}\right)$ and a positive relationship in Swingle (slope $=$ $0.06, R^{2}=0.433, P<0.001$ ).

Nutrients analysis in leaves. When expressed on a leaf DW basis, leaf nitrogen levels were reduced $(P<0.001)$ by girdling from the optimum range $\left(24-25 \mathrm{mg} \cdot \mathrm{g}^{-1}\right)$ to deficient levels $\left(18-20 \mathrm{mg} \cdot \mathrm{g}^{-1}\right)$ for citrus trees (Obreza and Morgan, 2008) in both rootstocks regardless of water status. Although other macronutrients generally were in the sufficient range, girdling also reduced leaf phosphorus $(\mathrm{P})$, potassium $(\mathrm{K})$, calcium (Ca), and magnesium ( $\mathrm{Mg}$ ) (data not shown). Similarly, girdling reduced all the measured micronutrients, leaf $\mathrm{B}$, zinc ( $\mathrm{Zn})$, manganese $(\mathrm{Mn}), \mathrm{Fe}$, and copper $(\mathrm{Cu})$ on a leaf DW basis, but almost all remained in the sufficient range (data not shown). Because leaf DW was increased by girdling (Fig. 2), levels of macro- and micronutrients were undoubtedly artificially decreased by leaf starch when expressed on a DW basis. To take this into account, both macro- and micronutrients were 


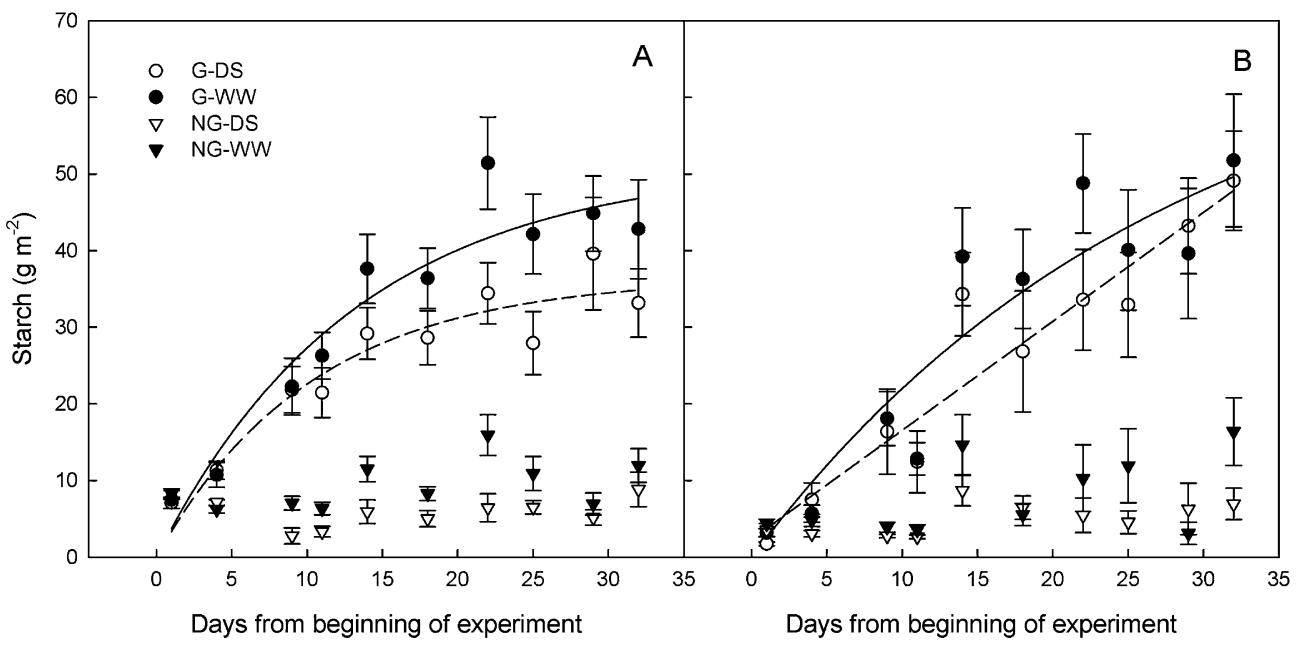

Fig. 3. Changes in starch content per unit leaf area during $31 \mathrm{~d}$ under various treatments $(\mathrm{NG}=$ non-girdled; $\mathrm{G}=$ girdled; $\mathrm{WW}=$ well-watered; $\mathrm{DS}=$ drought-stressed) and for the Cleopatra $(\mathbf{A})$ and Swingle $(\mathbf{B})$ seedlings. Error bars indicate sEMs $(\mathrm{n}=6)$. In Cleopatra, starch ${ }_{\mathrm{G}-\mathrm{Ww}}=51.3\left(1-0.93^{\mathrm{d}}\right), R^{2}=0.913$; $\operatorname{starch}_{\mathrm{G}-\mathrm{DS}}=36.5\left(1-0.91^{\mathrm{d}}\right), R^{2}=0.902$. In Swingle, $\operatorname{starch}_{\mathrm{G}-\mathrm{WW}}=72.1\left(1-0.96^{\mathrm{d}}\right), R^{2}=0.861 ; \operatorname{starch}_{\mathrm{G}-\mathrm{DS}}=2.35+1.42^{\mathrm{d}}, R^{2}=0.905$. All models are significant at $P<0.05$.
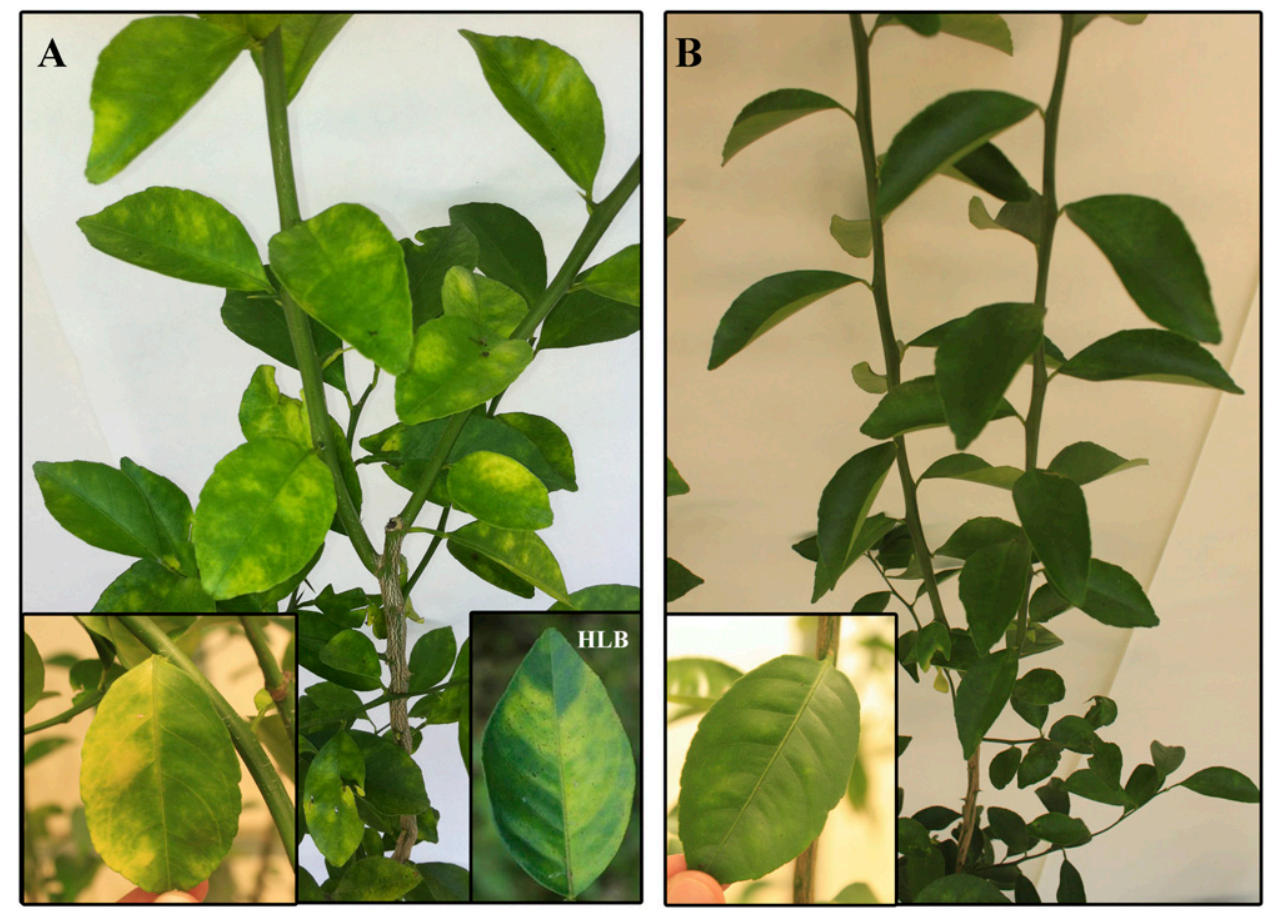

Fig. 4. Visual appearance of leaves from girdled (A and left inset) and non-girdled (B) Cleopatra trees after $31 \mathrm{~d}$ of treatment. For comparison, the lower right inset in $\mathbf{A}$ is an Huanglongbing (HLB)-positive leaf from the field.

Table 3. Starch content in woody and fibrous roots of the two rootstocks after $31 \mathrm{~d}$ of the various treatments.

\begin{tabular}{lcccc}
\hline & & & Woody & Fibrous \\
\cline { 3 - 5 } Rootstock & Girdling & Drought stress & $\left(\mathrm{mg} \cdot \mathrm{g}^{-1} \mathrm{DW}\right)$ & $\left(\mathrm{mg} \cdot \mathrm{g}^{-1} \mathrm{DW}\right)$ \\
\hline Cleopatra & NG & WW & 246.9 & 65.81 \\
& & DS & 294.8 & 117.4 \\
& $\mathrm{G}$ & WW & 32.60 & 18.28 \\
Swingle & DG & WW & 15.38 & 18.80 \\
& & DS & 108.40 & 47.27 \\
& G & WW & 26.75 & 59.53 \\
& & DS & 27.24 & 16.72 \\
& & HSD & 77.6 & 47.07 \\
\hline
\end{tabular}

$\overline{\mathrm{DW}}=$ dry weight; $\mathrm{NG}=$ non-girdled; $\mathrm{G}=$ girdled; $\mathrm{WW}=$ well-watered; $\mathrm{DS}=$ drought-stressed; $\mathrm{HSD}=$ Tukey's honestly significant difference at $P<0.05$. expressed on a LA basis. In this case, Cleopatra leaves had higher leaf $\mathrm{P}, \mathrm{Zn}, \mathrm{Fe}$, and $\mathrm{Cu}$ than Swingle leaves and girdling decreased $\mathrm{P}$, sulfur (S), and $\mathrm{Fe}$ above that of non-girdled leaves (Table 6). Girdling had no effect on leaf $\mathrm{Zn}$ and $\mathrm{Cu}$ and drought stress only decreased $\mathrm{Fe}$.

Girdling reduced leaf $\mathrm{Ca}$ in well-watered Cleopatra leaves but effects of girdling on most other nutrients disappeared when expressed on a LA basis (Table 7). Nongirdled Swingle leaves had higher $\mathrm{K}$ and $\mathrm{Mg}$ than Cleopatra but overall, Swingle had lower $\mathrm{Ca}, \mathrm{B}$, and $\mathrm{Mn}$ than Cleopatra. Drought stress reduced $\mathrm{B}$ and $\mathrm{Mn}$ in non-girdled Cleopatra. 
A
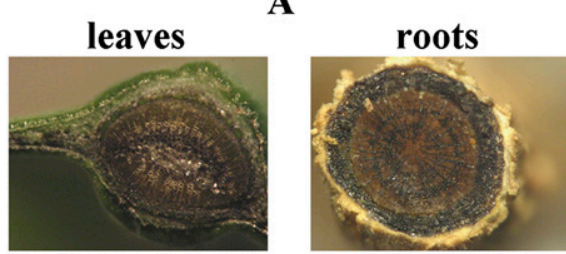

NG + WW

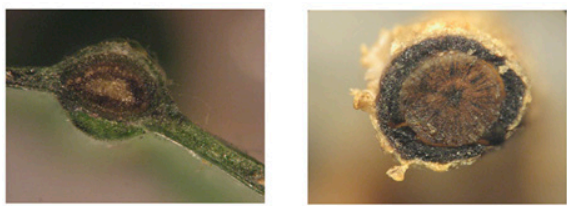

NG + DS

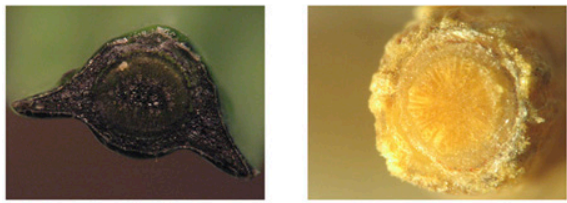

$\mathbf{G}+\mathbf{W W}$

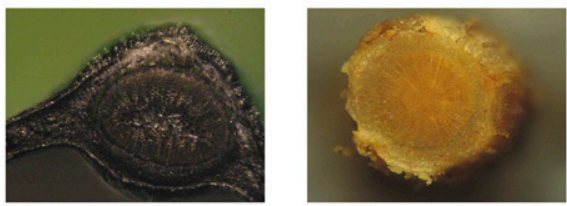

G + DS
B

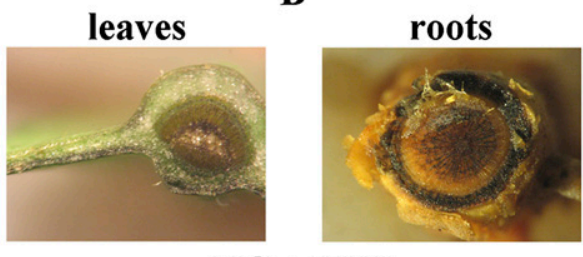

NG + WW

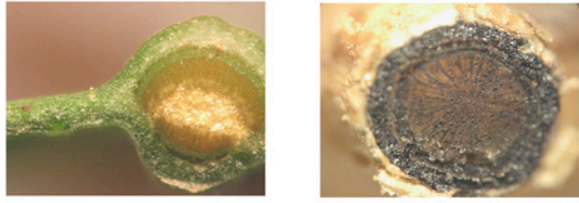

NG + DS

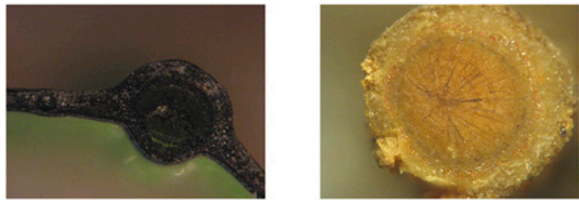

$\mathbf{G}+\mathbf{W W}$

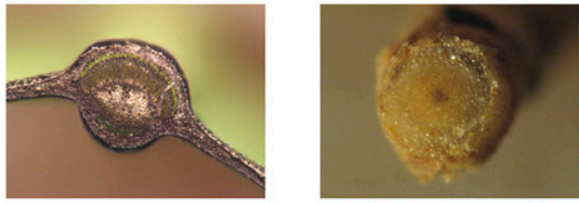

G + DS

Fig. 5. Starch determination by iodine staining in mature leaves and roots of Cleopatra $(\mathbf{A})$ and Swingle $(\mathbf{B})$ trees after $31 \mathrm{~d}$ of various treatments. NG $=$ nongirdled; G = girdled; WW = well-watered; DS = drought-stressed.

Table 4. Net photosynthesis $\left(\mathrm{ACO}_{2}, \mu \mathrm{mol} \cdot \mathrm{m}^{-2} \cdot \mathrm{s}^{-1}\right)$, transpiration $\left(\mathrm{E}_{\mathrm{lf}}, \mathrm{mmol} \cdot \mathrm{m}^{-2} \cdot \mathrm{s}^{-1}\right)$, water use efficiency (WUE, $\mu \mathrm{mol} \mathrm{CO}_{2} / \mathrm{mmol} \mathrm{H}_{2} \mathrm{O}$ ), stomatal conductance $\left(g_{\mathrm{S}} ; \mathrm{mol} \cdot \mathrm{m}^{-2} \cdot \mathrm{s}^{-1}\right)$, and the ratio of internal to ambient $\mathrm{CO}_{2}(\mathrm{Ci} / \mathrm{Ca}) 29 \mathrm{~d}$ after girdling in leaves of the two rootstocks under various treatments.

\begin{tabular}{lccccccc}
\hline Rootstock & Girdling & Drought stress & $\mathrm{ACO}_{2}$ & $\mathrm{E}_{1 \mathrm{f}}$ & WUE & $g_{\mathrm{s}}$ & $\mathrm{Ci} / \mathrm{Ca}$ \\
\hline Cleopatra & $\mathrm{NG}$ & $\mathrm{WW}$ & 8.13 & 3.13 & 2.60 & 0.16 & 0.76 \\
& & $\mathrm{DS}$ & 3.95 & 2.06 & 1.71 & 0.09 & 0.82 \\
& $\mathrm{G}$ & $\mathrm{WW}$ & 7.44 & 2.64 & 3.03 & 0.12 & 0.68 \\
\multirow{3}{*}{ Swingle } & $\mathrm{NG}$ & $\mathrm{DS}$ & 4.55 & 2.28 & 1.99 & 0.09 & 0.78 \\
& & WW & 11.3 & 4.16 & 2.74 & 0.24 & 0.78 \\
& $\mathrm{G}$ & $\mathrm{DS}$ & 6.80 & 1.68 & 4.06 & 0.07 & 0.59 \\
& & WW & 10.2 & 3.80 & 2.69 & 0.19 & 0.75 \\
& & $\mathrm{DS}$ & 8.52 & 2.59 & 3.33 & 0.13 & 0.71 \\
& & HSD & 4.07 & 1.44 & 1.20 & 0.08 & 0.12 \\
\hline
\end{tabular}

NG = non-girdled; G = girdled; WW = well-watered; DS = drought-stressed; HSD = Tukey's honestly significant difference at $P<0.05$.

Table 5. Stem water potential $(\mathrm{MPa})$ before watering (13 $\mathrm{d}$ from beginning of experiment) and after watering (16 $\mathrm{d}$ from beginning of experiment) trees of the two rootstocks under various treatments.

\begin{tabular}{lcccc}
\hline Rootstock & Girdling & Drought stress & Before & After \\
\hline Cleopatra & NG & WW & -1.87 & -0.93 \\
& & DS & -2.79 & -1.28 \\
& G & WW & -1.18 & -0.76 \\
Swingle & \multirow{2}{*}{ NG } & DS & -1.42 & -0.68 \\
& & WW & -1.39 & -1.03 \\
& \multirow{2}{*}{ G } & DS & -2.49 & -1.04 \\
& & WW & -0.89 & -0.68 \\
& & DS & -1.65 & -0.66 \\
& HSD & 0.61 & 0.25 \\
\hline
\end{tabular}

$\mathrm{NG}=$ non-girdled; $\mathrm{G}$ = girdled; $\mathrm{WW}=$ well-watered; DS = drought-stressed; HSD = Tukey's honestly significant difference at $P<0.05$.
Using all Swingle leaf B and starch values across both drought and girdling treatments, there was a significant negative relationship $(P<0.001)$ between leaf B and starch content when expressed on a LA basis (Fig. 6). The non-linear relationship revealed that most of the decrease in leaf B occurred with moderate increases in leaf starch and that the rate of decrease in leaf $\mathrm{B}$ decreased as leaf starch increased. However, there was no effect of leaf starch on leaf B in Cleopatra leaves.

\section{Discussion}

Based on visible changes and measurements of leaf starch and nutrient content, girdling induced similar effects to those caused by phloem dysfunction brought about by HLB. Because drought stress reduced stem RGR only in non-girdled trees, girdling also mitigated the effects of drought stress. Overall, girdling did not reduce stem RGR or induce any significant increase in stem diameter above the girdle meaning that the interruption of stem phloem did not greatly affect tree development of during the 31-d experiment. Longer-term studies have found that girdling reduced shoot growth and also induced thickening of the branch above the girdle of young citrus trees (Goren et al., 2004) as we too observed in main stems. The short duration of our experiment, however, was probably not sufficient to allow for changes in stem length or leaf area to occur.

Starch levels in new basal shoots were considerably lower than in counterpart mature leaves probably because of the reduced amount of carbon supplied by to the roots of girdled trees. Although new shoots of Swingle had a lower starch concentration than those of Cleo, all girdled trees did not produce basal shoots so additional rootstock comparisons were not possible.

Despite the fact the all treatments had a similar total LA, DW/LA was significantly higher in girdled than in non-girdled trees as a result of the high accumulation of starch in leaves that exceeded $50 \%$ of the leaf DW. It is possible that the magnitude of this response was related to the limited root growth in pots. Starch in leaves is known to accumulate 
Table 6. Leaf tissue macronutrients $\left(\mathrm{g} \cdot \mathrm{m}^{-2}\right.$ leaf area) and micronutrients $\left(\mathrm{mg} \cdot \mathrm{m}^{-2}\right.$ leaf area) in mature leaves of the two rootstocks after $31 \mathrm{~d}$ under various treatments. ${ }^{2}$

\begin{tabular}{lcccccc}
\hline Factor & Level & Phosphorus & Sulfur & Zinc & Iron & Copper \\
\hline Rootstock & Cleopatra & 0.123 & 0.223 & 5.49 & 5.04 & 6.37 \\
& Swingle & 0.084 & 0.213 & 3.88 & 4.34 & 1.47 \\
Girdling & $P$ & $<0.001$ & 0.404 & $<0.001$ & 0.002 & $<0.001$ \\
& $\mathrm{NG}$ & 0.107 & 0.231 & 4.85 & 4.90 & 4.05 \\
& $\mathrm{G}$ & 0.100 & 0.205 & 4.52 & 4.48 & 3.79 \\
Drought stress & $P$ & 0.047 & 0.037 & 0.351 & 0.045 & 0.695 \\
& $\mathrm{WW}$ & 0.105 & 0.224 & 4.63 & 5.04 & 4.43 \\
& $\mathrm{DS}$ & 0.102 & 0.212 & 4.73 & 4.34 & 3.41 \\
& $P$ & 0.452 & 0.282 & 0.774 & 0.002 & 0.125 \\
\hline
\end{tabular}

${ }^{\mathrm{z}}$ There were no significant interactions among main factors.

$\mathrm{NG}=$ non-girdled; G = girdled; WW = well-watered; DS = drought-stressed.

Table 7. Leaf tissue macronutrients $\left(\mathrm{g} \cdot \mathrm{m}^{-2}\right.$ leaf area) and micronutrients $\left(\mathrm{mg} \cdot \mathrm{m}^{-2}\right.$ leaf area) in mature leaves of the two rootstocks after $31 \mathrm{~d}$ under various treatments. ${ }^{\mathrm{z}}$

\begin{tabular}{|c|c|c|c|c|c|c|c|c|}
\hline Rootstock & Girdling & Drought stress & Nitrogen & Potassium & Magnesium & Calcium & Boron & Manganese \\
\hline \multirow[t]{4}{*}{ Cleopatra } & NG & WW & 2.04 & 1.35 & 0.31 & 1.56 & 5.79 & 2.10 \\
\hline & & DS & 1.81 & 1.14 & 0.24 & 1.38 & 4.37 & 1.36 \\
\hline & G & WW & 1.77 & 1.08 & 0.26 & 1.27 & 5.09 & 1.40 \\
\hline & & DS & 1.91 & 1.17 & 0.29 & 1.33 & 5.00 & 1.49 \\
\hline \multirow[t]{5}{*}{ Swingle } & NG & WW & 1.77 & 1.64 & 0.39 & 1.03 & 4.59 & 1.20 \\
\hline & & DS & 1.82 & 1.59 & 0.40 & 1.22 & 5.17 & 1.64 \\
\hline & G & WW & 1.80 & 1.55 & 0.34 & 0.94 & 3.84 & 1.35 \\
\hline & & DS & 1.72 & 1.36 & 0.33 & 0.94 & 4.04 & 1.44 \\
\hline & & HSD & 0.37 & 0.28 & 0.08 & 0.26 & 1.14 & 0.73 \\
\hline
\end{tabular}

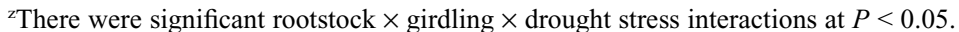

$\mathrm{NG}=$ non-girdled; $\mathrm{G}=$ girdled; $\mathrm{WW}=$ well-watered; $\mathrm{DS}=$ drought-stressed; HSD $=$ honestly significant difference.

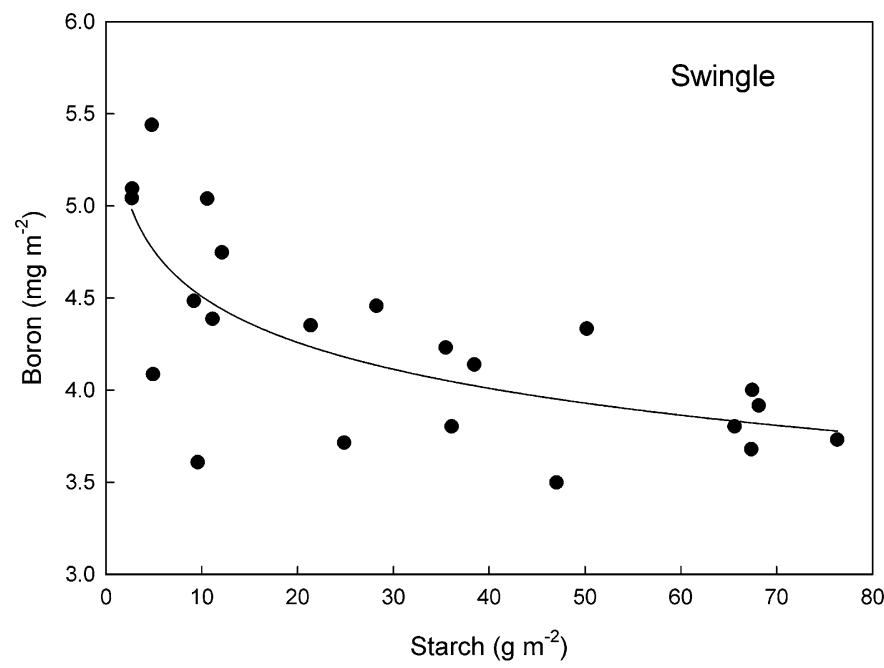

Fig. 6. Relationship between leaf starch and boron content on a leaf area (LA) basis in Swingle trees. Data from various treatments were pooled together. Boron $=5.34$ to $0.36 \mathrm{Ln}$ ( $\mathrm{starch}$ ), $R^{2}=0.512, P<0.001$.

during light periods and is mobilized at times of low photosynthetic activity in the dark to maintain a steady carbon supply to heterotrophic tissues. Citrus leaves, however, accumulate little starch under normal conditions (Yelenosky and Guy, 1977) but high amounts can accumulate as a result of Zn deficiency (Smith and Struckmeyer, 1974), cool winter temperatures, or girdling (Schaffer et al., 1986). Once accumulated, leaf starch in citrus tends not to be degraded (Goldschmidt and Koch, 1996), although some depletion of starch reserves may occur during root growth in winter months (Monerri et al., 2011). Citrus trees affected by HLB, however, accumulate considerable amounts of starch in practically every living cell of the aerial tree parts (Achor et al., 2010; Etxeberria et al., 2009). In HLB-affected leaves, not only photosynthetic cells and vascular parenchyma become saturated with starch, but phloem elements also develop starch granules (Folimonova and Achor, 2010).

After $31 \mathrm{~d}$, leaves on girdled trees accumulated four times more starch than control leaves. In girdled Swingle trees, for example, more than half of the total leaf DW was starch $\left(565 \mathrm{mg} \cdot \mathrm{g}^{-1} \mathrm{DW}\right)$. This represents $49.7 \mathrm{~g}$ starch $/ \mathrm{m}^{2}$ of leaf, in agreement with starch content reported in HLB-infected trees
(30-60 g. $\left.\mathrm{m}^{-2}\right)$ and also in field citrus trees $\left(64 \mathrm{~g} \cdot \mathrm{m}^{-2}\right)$ over a period of 3 months after girdling (Gonzalez et al., 2009). Although differences between starch in well-watered and drought-stressed treatments were not significant, drought stress consistently reduced leaf starch. $\mathrm{Vu}$ and Yelenosky (1989) also reported a negative impact of a 10-d water deficit period on starch and sucrose contents in leaves of citrus trees.

One of the most visible symptoms of HLB, the blotchy mottled yellowing of leaves, is believed to be a result from the disintegration of the chloroplast thylakoid system caused by massive starch accumulation (Etxeberria et al., 2009; Gonzalez et al., 2012). Here, we were able to induce the asymmetric, blotchy mottled chlorotic symptoms with starch accumulation in the absence of HLB (Fig. 4). These are symptoms closely corresponded to those previously described as specifically diagnostic for HLB (Achor et al., 2010; Spann and Schumann, 2009).

Girdling did not induce any measurable increase of foliar sucrose in our experiments. Goldschmidt and Huber (1992) and Mebelo et al. (1998) suggested that any temporary surplus of sucrose is cycled into free hexoses, glucose, and fructose. The reduced starch levels in both woody and fibrous roots by girdling were also found by Li et al. (2003) in girdled citrus trees when compared with nongirdled trees. In their case, starch-iodine staining also confirmed the quantitative reductions of starch in the root vascular cylinder in response to girdling. This supported our hypotheses both in terms of the interruption of the downward translocation of photosynthetic carbohydrates through the phloem (as a result of girdling) and in terms of the mobilization of starch reserve during the experiment. Reductions of carbohydrates in roots of girdled trees can also result in reduced root growth and functionality, especially in terms of active ion uptake (Hershey and Paul, 1983; Salisbury and Ross, 1985).

Many reports have suggested that accumulation of starch can limit photosynthesis by end product inhibition (Iglesias et al., 2002; Jifon and Syvertsen, 2003; Syvertsen et al., 2003), by physical limitations on $\mathrm{CO}_{2}$ diffusion, or by the rupturing of chloroplasts (Bondada and Syvertsen, 2005; De Menezes de Assis et al., 2003; Paul and Foyer, 2001). However, we did not observe any significant reduction of the variable $\mathrm{ACO}_{2}$ responses to girdling despite the massive starch accumulation in leaves of girdled trees (Fig. 3). In addition, there were no negative correlations between starch level and $\mathrm{CO}_{2}$ fixation (data not shown). In citrus leaves, high rates of photosynthesis are apparently possible even in those with high carbohydrate content under natural conditions (Ribeiro and Machado, 2007). This observation suggests that the amount of leaf carbohydrate itself may not be directly related to changes in photosynthesis. It is possible that photosynthesis in citrus leaves is regulated by leaf sucrose and its short-term dynamics rather than by starch content. In that case, photosynthetic levels 
would be maintained by diverting glucose to starch rather than to sucrose.

Under these greenhouse conditions, we observed a decrease in photosynthesis in response to drought stress in Swingle leaves but not in Cleopatra leaves. Similar effects were described in leaves of 'Valencia' orange trees (De Menezes de Assis et al., 2003; Vu and Yelenosky, 1989). We also found opposite trends in the two rootstocks for $\mathrm{Ci} / \mathrm{Ca}$ in response to $\mathrm{WP}_{\mathrm{S}}$, negative in Cleopatra and positive in Swingle. Because $\mathrm{Ci} / \mathrm{Ca}$ declines when $g_{\mathrm{s}}$ declines, this implied that drought stress inhibited leaf photosynthetic $\mathrm{CO}_{2}$ assimilation through stomatal limitations in Swingle and through non-stomatal limitations in Cleopatra. Thus, in Cleopatra, decreases in $\mathrm{ACO}_{2}$ must have been a direct effect of low $\mathrm{WP}_{\mathrm{S}}$ on $\mathrm{ACO}_{2}$ as suggested in other studies (Farquhar and Sharkey, 1982; Peréz-Peréz et al., 2007) rather than by indirect limitations of $g_{\mathrm{s}}$ on $\mathrm{ACO}_{2}$ as occurred in Swingle leaves.

The prominent increase in leaf DW resulting from starch accumulation can lead to erroneous conclusions in the analysis of nutrient changes (Spann and Schumann, 2009). When leaf nutrients were expressed on a LA basis, girdling only reduced leaf $\mathrm{P}, \mathrm{S}, \mathrm{Fe}$, and sometimes $\mathrm{Ca}$. Non-linear regression analysis, however, revealed a decrease in leaf B as starch increased in Swingle leaves, especially at relatively low levels of $\mathrm{B}$ and starch expressed on a LA basis. This may indicate a more direct link between $B$ accumulation and carbon translocation rather than between $\mathrm{B}$ and starch concentration.

Boron is one of the most important micronutrients for citrus trees (Roy, 1943; Srivastava and Singh, 2005) and a decrease in leaf B has been associated with HLB (Spann and Schumann, 2009). Working with experimental citrus trees growing under low B conditions, Hass and Klotz (1931) described morphological symptoms as "internal girdling" because of the breakdown of the phloem tissues and a concomitant reduction in translocation. This low B treatment also resulted in a high concentration of carbohydrates in leaves. We demonstrated that an accumulation of starch, independent of HLB, can be associated with a decrease in leaf $B$ even when expressed on a LA basis. This is an important outcome because it describes a new relationship between leaf starch and B in the absence of HLB disease. In girdled Cleo trees, however, there was no correlation between leaf nutrients and leaf starch indicating that these relationships were speciesspecific. Reductions in other leaf nutrients were not proportional to increase in leaf starch and could have been directly related to loss of root functionality (decreased growth or respiration) for active ion uptake that again could generate deficiency symptoms similar to those of HLB-infected trees.

\section{Conclusions}

By increasing leaf starch and decreasing root starch by stem girdling citrus trees, we reproduced blotchy mottled symptoms in leaves that have been associated with HLBinfected trees. When leaf nutrients were expressed on a LA basis, girdling reduced leaf $\mathrm{P}, \mathrm{S}, \mathrm{Fe}$, and sometimes $\mathrm{Ca}$. In the absence of HLB, girdling decreased water use. Increasing leaf starch decreased leaf B even when expressed on a LA basis. This supports our contention that visible symptoms generally attributed to HLB are not necessarily related to the infection, but rather are directly related to starch allocation and and/or nutrient deficiencies.

\section{Literature Cited}

Achor, D.S., E. Etxeberria, N. Wang, S.Y. Folimonova, K.R. Chung, and L.G. Albrigo. 2010. Sequence of anatomical symptom observations in citrus affected with Huanglongbing disease. Tree Pathol. J. 9:56-64.

Beruter, J. and M.E.S. Feusi. 1997. The effect of girdling on carbohydrate partitioning in the growing apple fruit. J. Tree Physiol. 151:277285.

Bondada, B.R. and J.P. Syvertsen. 2005. Concurrent changes in net $\mathrm{CO}_{2}$ assimilation and chloroplast ultrastructure in nitrogen deficient citrus leaves. Environ. Exp. Bot. 54:41-48.

Bove, J.M. 2006. Huanglongbing: A destructive, newly-emerging, century-old disease in citrus. J. Tree Pathol. 88:7-37.

Cutting, J.G.M. and M.C. Lyne. 1993. Girdling and the reduction in shoot xylem sap concentrations of cytokinins and gibberellins in peach. J. Hort. Sci. 68:619-626.

De Menezes de Assis, G.M., A.M. Magalhaes Andrade Lagoa, E. Caruso Machado, C.L. Median, and M.A. Machado. 2003. Gas exchanges and carbohydrate metabolism in orange trees with citrus variegated chlorosis. Braz. J. Tree Physiol. 15:25-31.

Etxeberria, E., P. Gonzalez, D. Achor, and G. Albrigo. 2009. Anatomical distribution of abnormally high levels of starch in HLB-affected Valencia orange trees. Physiol. Mol. Tree Pathol. 74:76-83.

Farquhar, G.D. and T.D. Sharkey. 1982. Stomatal conductance and photosynthesis. Annu. Rev. Tree. Physiol. 33:317-345.

Folimonova, S.Y. and D. Achor. 2010. Early events of citrus greening (Huanglongbing) disease development at the ultrastructural level. Bacteriology 100:949-958.

Garnier, M. and J.M. Bove. 1983. Transmission of the organism associated with citrus greening disease from sweet orange to periwinkle by dodder. Phytopathology 73:1358-1363.

Goldschmidt, E.E. and S.C. Huber. 1992. Regulation of photosynthesis by end-product accumulation in leaves of trees storing starch, sucrose and hexose sugars. Tree Physiol. 99:14431448.

Goldschmidt, E.E. and K.E. Koch. 1996. Citrus, p. 797-823. In: Zamski, E. and A.A. Schaffer (eds.). Marcel Dekker, New York, NY.

Gonzalez, P., E. Etxeberria, D. Achor, G. Albrigo, W. Dawson, and T. Spann. 2009. Uso de la reaccion almidon yodo para la seleccion de hojas sospechosas con HLB: Distribucion anatomica del almidon en arboles positivos al HLB. Ponencia 1er encuentro Internacional de Investigacion en Citricos, 3-5 Agosto. Martinez de la Torre, Veracruz, Mexico.

Gonzalez, P., J. Reyes-De-Corcuera, and E. Etxeberria. 2012. Characterization of leaf starch from HLBaffected and unaffected-girdled citrus trees. Physiol. Mol. Tree. Pathol. 79:71-78.
Goren, R., M. Huberman, and E.E. Goldschmidt. 2004. Girdling: Physiological and horticultural aspects, p. 1-36. In: Janick, J. (ed.). Horticulture reviews. Wiley, NJ.

Hass, A.R.C. and L.J. Klotz. 1931. Some anatomical and physiological changes in citrus produced by boron deficiency. Hilgardia 5:175-196.

Hershey, D.R. and J.L. Paul. 1983. Ion absorption by a woody tree with episodic growth. HortScience 18:357-359.

Hu, L.M., R.X. Xia, Z.Y. Xiao, R.H. Huang, M.L. Tan, M.Y. Wang, and Q.S. Wu. 2007. Reduced leaf photosynthesis at midday in citrus leaves growing under field or screenhouse conditions. J. Hort. Sci. Biotechnol. 82:387-392.

Iglesias, D.J., I. Lliso, F.R. Tadeo, and M. Talon. 2002. Regulation of photosynthesis through source-sink imbalance in citrus is mediated by carbohydrate content in leaves. Physiol. Tree. 116:563-572.

Jagoueix, S., J.M. Bove, and M. Garnier. 1994. The phloem-limited bacterium of greening disease of the protobacteria is a member of the alpha subdivision of the Proteobacteria. Intl. J. Syst. Bacteriol. 44:379-386.

Jang, J.C. and J. Sheen. 1997. Sugar sensing in higher trees. Trends Tree Sci. 2:208-214.

Jifon, J.L. and J.P. Syvertsen. 2003. Moderate shade can increase net gas exchange and reduce photoinhibition in citrus leaves. Tree Physiol. 23:119-127.

Koch, K.E. and Y. Zeng. 2002. Molecular approaches to altered $\mathrm{C}$ partitioning: Genes for sucrose metabolism. J. Amer. Soc. Hort. Sci. 127:474-483.

Li, C.Y., D. Weiss, and E.E. Goldschmidt. 2003. Girdling affects carbohydrate-related gene expression in leaves, bark and roots of alternatebearing citrus trees. Ann. Bot. (Lond.) 92:137143.

Mebelo, M., T. Shigeto, and K. Itaru. 1998. The effect of time of girdling on carbohydrate contents and fruiting in Ponkan mandarin (Citrus reticulata Blanco). Sci. Hort. 73:203-211.

Monerri, C., A. Fortunato-Almeida, R.V. Molina, S.G. Nebauer, A. García-Luis, and J.L. Guardiola. 2011. Relation of carbohydrate reserves with the forthcoming crop, flower formation and photosynthetic rate, in the alternate bearing 'Salustiana' sweet orange (Citrus sinensis L.). Sci. Hort. 129:71-78.

Noel, A.R.A. 1970. The girdled tree. Bot. Rev. $36: 162-193$

Obreza, T.A. and K.T. Morgan (eds.). 2008. Nutrition of Florida citrus trees. 2nd Ed. University of Florida-IFAS, Soil and Water Science Department, FL. SL 253.

Paul, M.J. and C.H. Foyer. 2001. Sink regulation of photosynthesis. J. Expt. Bot. 52:1383-1400.

Peréz-Peréz, J.G., J.P. Syvertsen, P. Botía, and F García-Sanchez. 2007. Leaf water relations and net gas exchange responses of salinized Carrizo citrange seedlings during drought stress and recovery. Ann. Bot. (Lond.) 100:335-345.

Ribeiro, R.V. and E.C. Machado. 2007. Some aspects of citrus ecophysiology in subtropical climates: Re-visiting photosynthesis under natural conditions. Braz. J. Tree. Physiol. 19:393-411.

Rosales, R. and J.K. Burns. 2011. Phytohormone changes and carbohydrate status in sweet orange fruit from Huanglongbing-infected trees. J. Tree Growth Regul. 30:312-321.

Roy, W.R. 1943. Studies of boron deficiency in grapefruit. Proc. Fla. State Hort. Soc. 56:38-43. Salisbury, F.B. and C.W. Ross. 1985. Tree physiology. 3rd Ed. Wadsworth Publishing Co., Belmont, CA. Schaffer, A., K.-C. Liu, E. Goldschmidt, C.D. Boyer, and R. Goren. 1986. Citrus leaf chlorosis 
induced by sink removal: Starch nitrogen and chloroplast ultrastructure. J. Tree Physiol. 124: 111-121.

Smeekens, S. 2000. Sugar-induced signal transduction in trees. Annu. Rev. Tree Mol. Biol. Tree Physiol. 51:49-81.

Smith, D. and B. Struckmeyer. 1974. Gross morphology and starch accumulation in leaves of alfalfa trees grown at high and low temperatures. Crop Sci. 14:433-436.

Spann, T.M. and A.W. Schumann. 2009. The role of tree nutrients in disease development with emphasis on citrus and huanglongbing. Proc. Fla. State Hort. Soc. 122:169-171.

Srivastava, A.K. and S. Singh. 2005. Boron nutrition in citrus - Current status and future strategies- $\mathrm{A}$ review. Agr. Rev. 26:173-186.

Syvertsen, J.P., C. Goni, and A. Otero. 2003. Fruit load and canopy shading affect leaf photosynthesis and carbohydrate status in 'Spring' navel orange trees. Tree Physiol. 23:899906.

Van Handel, E. 1968. Direct micro-determination of sucrose. Anal. Biochem. 22:280-283.
Vu, J.C.V. and G. Yelenosky. 1989. Non-structural carbohydrate concentrations in leaves of 'Valencia' orange subjected to water deficits. Environ. Exp. Bot. 29:149-154.

Weaver, R.J. and S.B. McCune. 1959. Girdling: In relation to carbohydrate nutrition and development of Thompson Seedless, Red Malaga and Ribier grapes. Hilgardia 28:421-456.

Yelenosky, G. and C.L. Guy. 1977. Carbohydrate accumulation in leaves and stems of 'Valencia' orange at progressively colder temperatures. Bot. Gaz. 138:13-17. 